\title{
Observing Effects of Calcium/Magnesium Ions and pH Value on the Self-Assembly of Extracted Swine Tendon Collagen by Atomic Force Microscopy
}

\author{
Xuan Song, ${ }^{1}$ Zhiwei Wang, ${ }^{1}$ Shiyu Tao, ${ }^{1}$ Guixia Li, ${ }^{1}$ and Jie Zhu ${ }^{1,2,3}$ \\ ${ }^{1}$ Laboratory of Agricultural and Food Biomechanics, Institute of Biophysics, College of Science, Northwest A\&F University, \\ Yangling, Shaanxi 712100, China \\ ${ }^{2}$ Sino-US Joint Research Center of Food Safety, Northwest A\&F University, Yangling, Shaanxi 712100, China \\ ${ }^{3}$ Department of Animal Sciences, College of Agriculture, Purdue University, West Lafayette, IN 47907, USA
}

Correspondence should be addressed to Jie Zhu; jiezhu@nwafu.edu.cn

Received 26 October 2016; Revised 7 May 2017; Accepted 1 June 2017; Published 16 July 2017

Academic Editor: Susana Fiszman

Copyright (C) 2017 Xuan Song et al. This is an open access article distributed under the Creative Commons Attribution License, which permits unrestricted use, distribution, and reproduction in any medium, provided the original work is properly cited.

\begin{abstract}
Self-assembly of extracted collagen from swine trotter tendon under different conditions was firstly observed using atomic force microscopy; then the effects of collagen concentration, $\mathrm{pH}$ value, and metal ions to the topography of the collagen assembly were analyzed with the height images and section analysis data. Collagen assembly under $0.1 \mathrm{M}, 0.2 \mathrm{M}, 0.3 \mathrm{M} \mathrm{CaCl}_{2}$, and $\mathrm{MgCl}_{2}$ solutions in different $\mathrm{pH}$ values showed significant differences $(P<0.05)$ in the topographical properties including height, width, and roughness. With the concentration being increased, the width of collagen decreased significantly $(P<0.05)$. The width of collagen fibers was first increased significantly $(P<0.05)$ and then decreased with the increasing of $\mathrm{pH}$. The collagen was assembled with network structure on the mica in solution with $\mathrm{Ca}^{2+}$ ions. However, it had shown uniformed fibrous structure with $\mathrm{Mg}^{2+}$ ions on the new cleaved mica sheet. In addition, the width of collagen fibrous was $31 \sim 58 \mathrm{~nm}$ in solution with $\mathrm{Mg}^{2+}$ but $21 \sim 50 \mathrm{~nm}$ in Ca solution. The self-assembly collagen displayed various potential abilities to construct fibers or membrane on mica surfaces with $\mathrm{Ca}^{2+}$ ions and $\mathrm{Mg}^{2+}$ irons. Besides, the result of collagen self-assembly had shown more relations among solution $\mathrm{pH}$ value, metal ions, and collagen molecular concentration, which will provide useful information on the control of collagen self-assembly in tissue engineering and food packaging engineering.
\end{abstract}

\section{Introduction}

As the most abundant proteins in human and animals, collagen does occupy $1 / 3$ of the whole body proteins and is distributed in almost all tissues and organs [1]. More than twenty specialized types of collagen have been characterized, in the form of fibers in connective tissues or membranes in extracellular matrix. As the primary structural proteins in connective tissues, type I collagen is a major component of tendon, cartilage, ligament, bone, skin, and cornea [2]. It was known that the collagen molecule is composed of three polypeptide chains with a right-handed triple-helical structure [3]. Compared with other proteins, the form of collagen is determined by the amino acids sequences of the $\alpha$-chains that come together to maximize hydrophobic and charge attractions between them [4]. In addition, more than half of all hydrophobic residues are toward the outside, which makes the triple-helical polypeptide chains of collagen assemble into microfibrils from fibrils genesis, thus forming larger collagen bundles [5].

Collagen molecules have the ability to self-assemble from solution and the most types of collagen molecules participate in some form of higher-order supramolecular self-assembly that directly relates to their biological function [6]. Selfassembly is a process during which collagen molecules form in a highly-ordered way into an aggregate embossed with biological functions through the interactions of secondary bond. The electron microscopy and X-ray were used to observe the solubilized collagen molecules and aggregates spontaneously assembled to form fibrils with the characteristic $67 \mathrm{~nm}$ fibrils 
repeat distance under $37^{\circ} \mathrm{C}$ [7]. And there are some researches which found that ultrastructural insights revealed by electron microscopy and X-ray diffraction indicate that tendon fibers consist of building blocks separated by average periodicities around 4-5 nm [8]. From these results, models of collagen self-assembly into microfibrils could be developed. In vivo, type I collagen molecules are assembled into fibrillar or membranes structures when the collagen solution is adjusted to specific concentration of collagen, $\mathrm{pH}$, and ionic strength, which can be applied in the composition of engineering scaffolds of bones, cartilage, skin, muscles, or food packaging engineering materials for its structural features and biological characteristics. Therefore, the research on collagen can be promoted as a potential source in regenerative medicine and food packaging $[9,10]$.

Collagen properties are sensitive to $\mathrm{pH}$ and ionic strength because these conditions affect the self-assembly of collagen monomers into fibrils. Thus, the effects of $\mathrm{pH}$ value and metal ions concentrations on self-assembly of type I collagen molecules were investigated and evaluated in this study with atomic force microscopy (AFM) which is an efficient and widely used method on molecular and cellular biology for its high resolution and simple sample preparation [11]; the change of appearance of collagen self-assembly under different condition was observed by AFM. In addition, the mechanism of collagen self-assembly under different $\mathrm{pH}$ and metal irons was explained in this report, systematically.

\section{Materials and Methods}

2.1. Preparation of Collagen Solutions. Tendon tissues for collagen purification were dissected from the fresh swine trotter, which was purchased from Yangling Trust-Mart at Shaanxi, China. The tendon tissues were firstly cut into $\sim 0.3 \mathrm{~cm}^{3}$ cubes and homogenized intermittently in $0.9 \% \mathrm{NaCl}$ using T10 IKA homogenizer (IKA Co., Germany) [12]. After being washed with $0.9 \% \mathrm{NaCl}$ for more than 5 times, the tendons homogenates were mixed with $0.5 \mathrm{M}$ Tris- $\mathrm{HCl}(\mathrm{pH}=7.5)$ containing $1 \mathrm{M} \mathrm{NaCl}$ at a tendon/solution ratio of $1: 25(\mathrm{w} / \mathrm{v})$ and immediately placed in $4^{\circ} \mathrm{C}$ refrigerator for $24 \mathrm{~h}$ with stirring every $8 \mathrm{~h}$, then discarding the supernatant to remove the noncollagenous impurities. After being fully washed with distilled water, the tendon sediment was extracted for collagen molecules by adding $100 \mathrm{ml} 0.5 \mathrm{M}$ acetic acid at $4^{\circ} \mathrm{C}$ for $24 \mathrm{~h}$. Then, the collagen solution was filtered and precipitated by adding $20 \% \mathrm{NaCl}$. When the floe occurred, the above collagen was collected by centrifugation at $10,280 \mathrm{~g}$ for $30 \mathrm{~min}$ and then was redissolved by $0.5 \mathrm{M}$ acetic acid with the final collagen concentration of $4 \mathrm{mg} / \mathrm{ml}$; finally it was stored at $4^{\circ} \mathrm{C}$ in order to avoid microbial contamination and denaturation $[13,14]$. The $\mathrm{pH}$ of original collagen solution was adjusted to 7.0 before use.

2.2. Self-Assembly of Collagen in Different Concentrations. Stock solution of $\mathrm{Na}_{2} \mathrm{HPO}_{4}$ and $\mathrm{NaH}_{2} \mathrm{PO}_{4}$ was prepared with distilled water and the $\mathrm{pH}$ value was adjusted to 9.2 with $0.1 \mathrm{M} \mathrm{NaOH}$ in this experiment. The original solution of collagen $(4 \mathrm{mg} / \mathrm{ml}, \mathrm{pH}=7.0)$ was diluted with phosphate buffer to the final concentration at $0.1 \mathrm{mg} / \mathrm{ml}, 0.2 \mathrm{mg} / \mathrm{ml}$, and $0.3 \mathrm{mg} / \mathrm{ml}$, respectively. Then, three kinds of $20 \mu \mathrm{l}$ diluted collagen solutions were deposited onto a fresh cleaved mica surface separately. They were put into perforated plate and dried at room temperature. Finally they were observed under AFM after the sample dried.

2.3. Self-Assembly of Collagen in Different $p H$ Values. The $\mathrm{pH}$ value of the phosphate buffer was adjusted to 5.7, 7.0, 8.0, and 9.2 with $0.1 \mathrm{M} \mathrm{NaOH}$, and the original collagen solution ( $4 \mathrm{mg} / \mathrm{ml}, \mathrm{pH}=7.0$ ) was dissolved in phosphate buffer with the different $\mathrm{pH}$ values to make the final concentration at $0.2 \mathrm{mg} / \mathrm{ml}$ of all the samples $[15,16] .20 \mu \mathrm{l}$ collagen solution was dropped onto the fresh cleaved mica surface, which was dried at room temperature and washed several times with distilled water, avoiding the interference of crystals derived from phosphate buffer.

2.4. Self-Assembly of Collagen in Different Metal Ions and Concentrations. Distilled water was used to formulate $\mathrm{CaCl}_{2}$ and $\mathrm{MgCl}_{2}$ solutions at concentration of $0.1,0.2$, and $0.3 \mathrm{M}$. The original collagen solution $(4 \mathrm{mg} / \mathrm{ml}, \mathrm{pH}=7.0)$ was diluted into $1 \mathrm{mg} / \mathrm{ml}$ and $200 \mu \mathrm{l}$ of this solution was mixed with different concentrations of $\mathrm{CaCl}_{2} / \mathrm{MgCl}_{2}$ solution at $160 \mu \mathrm{l}$ and $640 \mu \mathrm{l}$ Tris- $\mathrm{HCl}(0.05 \mathrm{M}, \mathrm{pH}=7.5)$. In the control group, the collagen solution $(1 \mathrm{mg} / \mathrm{ml})$ was mixed with $800 \mu \mathrm{l}$ Tris$\mathrm{HCl}$ only [17]. After being fully mixed, $20 \mu \mathrm{l}$ of the solution was drawn and dropped onto fresh cleaved mica surface, then placed into perforated plate, naturally dried at room temperature, and observed with AFM.

2.5. AFM Imaging and Data Analysis. All tests were executed on Multimode 8 AFM with SCANASYST-AIR probes (Bruker Co., Santa Barbara, CA) in ScanAsyst mode at $0.997 \mathrm{~Hz}$. Height and error images in $512 \times 512$ pixels were collected simultaneously to be flattened, erased, and analyzed using AFM image processing offline software NanoScope Analysis V1.10 (Bruker Co., Santa Barbara, CA) [18]. The qualitative data of collagen fibrils width, height, and root-mean-square (Rms) roughness was recorded as mean \pm SE (standard error). All statistical analyses were performed using IBM SPSS 17.0. An analysis of variance (ANOVA) was used to determine the differences among the treatments. Fisher's Protected Least Significant Difference (LSD) test was set at a $5 \%$ significance level and evaluated by Duncan's multiple range test to estimate the levels of statistical significance $(P<$ 0.05). For each sample, at least 5 AFM images were randomly captured and at least 10 different fibrils were selected from each image.

\section{Results and Analysis}

3.1. Effects of Collagen Concentration on the Self-Assembly. In Figure 1, formulated collagen solutions of different concentrations with phosphate buffer $(\mathrm{pH}=9.2)$ and typical AFM height images and section analysis profiles results are shown and the figure discusses the changes of structure. The structure of collagen self-assembly is directional at some 

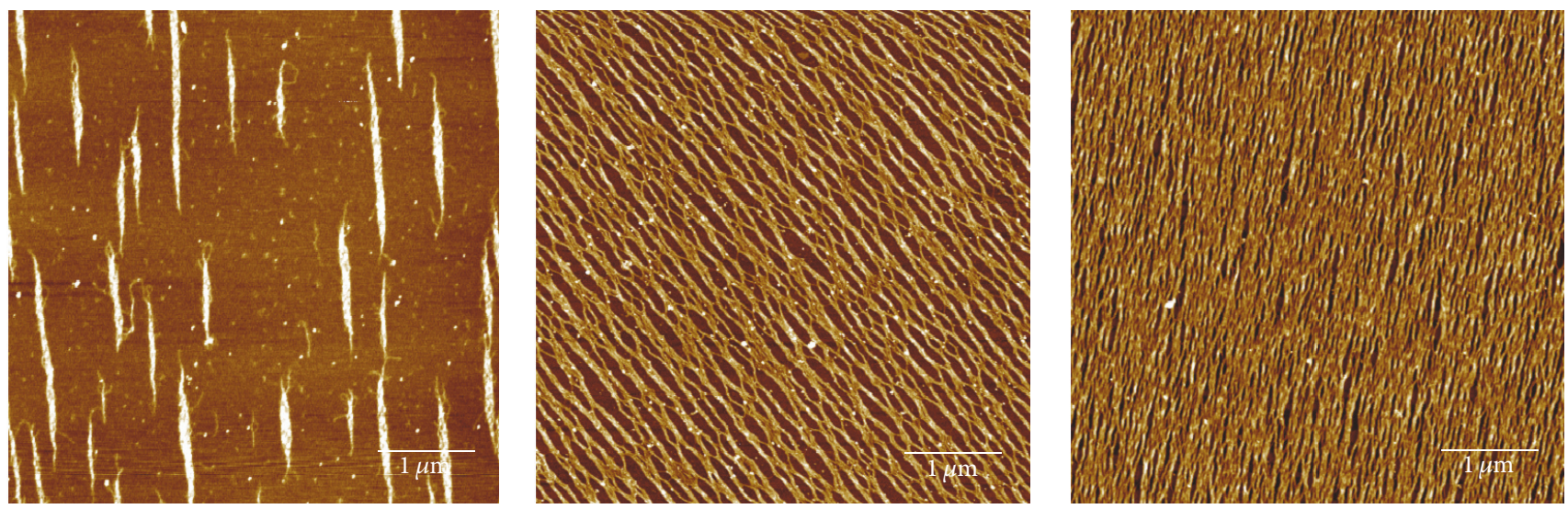

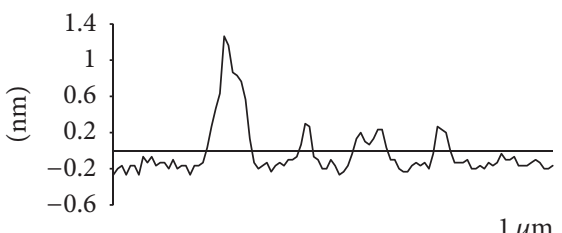

(a)

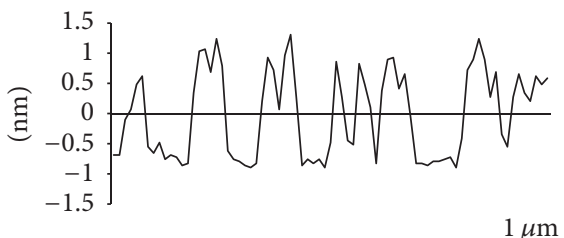

(b)

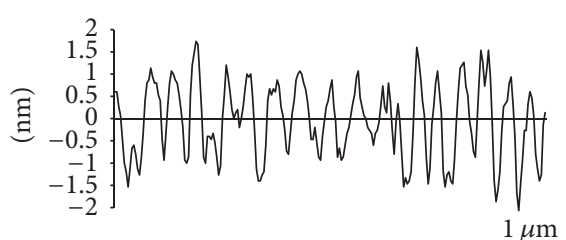

(c)

FIGURE 1: Typical AFM height images and section analysis profiles of collagen self-assembly in different concentrations in $512 \times 512$ pixels: (a) $0.1 \mathrm{mg} / \mathrm{ml}$; (b) $0.2 \mathrm{mg} / \mathrm{ml}$; (c) $0.3 \mathrm{mg} / \mathrm{ml}$.

TABLE 1: Width, height, and roughness of the collagen self-assembly in different collagen concentrations.

\begin{tabular}{lccc}
\hline Parameter & \multicolumn{3}{c}{ Concentration } \\
& $0.1 \mathrm{mg} / \mathrm{ml}$ & $0.2 \mathrm{mg} / \mathrm{ml}$ & $0.3 \mathrm{mg} / \mathrm{ml}$ \\
\hline Width/nm & $138.10 \pm 8.06^{\mathrm{a}}$ & $103.5 \pm 10.09^{\mathrm{b}}$ & $46.50 \pm 5.11^{\mathrm{c}}$ \\
Height $/ \mathrm{nm}$ & $1.37 \pm 0.09^{\mathrm{c}}$ & $1.73 \pm 0.13^{\mathrm{b}}$ & $2.29 \pm 0.15^{\mathrm{a}}$ \\
Roughness/nm & $0.32 \pm 0.01^{\mathrm{c}}$ & $0.70 \pm 0.04^{\mathrm{b}}$ & $0.86 \pm 0.11^{\mathrm{a}}$
\end{tabular}

Results $(n=20)$ are shown as mean \pm SE. Means without common superscripts $(\mathrm{a}-\mathrm{c})$ in row are different $(P<0.05)$.

degree and the fiber structure is very clear in phosphate buffer. At low concentration, collagen combined into small and short parallel distributed collagen fibers with the length varies from $0.8 \mu \mathrm{m}$ to $1.6 \mu \mathrm{m}$, as shown in Figure 1(a). As the concentrations increased, the width of collagen fibers decreased significantly $(P<0.05)$, and these parallel collagen fibers were crosslinked by some thinner fibers, forming a kind of network self-assembly structure. The width and height of collagen fibers in different concentrations were reflected in section analysis profiles below the corresponding height images, and the date of Rms roughness was calculated automatically, as shown in Table 1.

As the collagen concentration increased from $0.1 \mathrm{mg} / \mathrm{ml}$ to $0.3 \mathrm{mg} / \mathrm{ml}$, the space between the collagen fibers decreased obviously, in which the width of collagen self-assembly was decreased from $138.10 \pm 8.06 \mathrm{~nm}$ to $46.50 \pm 5.11 \mathrm{~nm}$, the height was increased from $1.37 \pm 0.09 \mathrm{~nm}$ to $2.29 \pm$ $0.15 \mathrm{~nm}$, and Rms roughness increased from $0.32 \pm 0.01 \mathrm{~nm}$ to $0.86 \pm 0.11 \mathrm{~nm}$; and the differences among width, height, and roughness of collagen self-assembly were significant
$(P<0.05)$. It was demonstrated that, in the lower collagen concentrations, collagen molecules firstly formed into single short fibrils through axial connection and, with the collagen concentrations increasing gradually, the single fibrils would be axially connected to longer fibrils and even formed into dense network structure through the crosslinking between these small fibrils $[19,20]$.

3.2. Effects of pH Values on the Collagen Self-Assembly. To investigate the $\mathrm{pH}$ influence on the collagen self-assembly, typical AFM height images of self-assembly collagen dissolved by phosphate buffer at a series of $\mathrm{pH}$ values showed obvious topological diversity in Figure 2. The collagen molecules were absorbed and assembled onto fresh cleaved mica as fiber protrusions at $\mathrm{pH}$ 5.7, as shown in Figure 2(a), in which the mica surface was completely covered with fibrillar structures with the randomly distributed dense fibers. Therefore, the width of collagen fibrils was relatively smaller in acidic solution than the others. The self-assembled structures were gradually transformed into a fibrous structure and the fibrils were mostly parallel to others as acidic samples weakened in Figures 2(b)-2(d).

The influences of $\mathrm{pH}$ values on the collagen self-assembly were quantified and shown in Table 2. Firstly, the width of collagen self-assembly increased dramatically and then decreased significantly $(P<0.05)$ when the $\mathrm{pH}$ values were adjusted from 5.7 to 9.2. The height and Rms roughness decreased when the $\mathrm{pH}$ values increased except at $\mathrm{pH} 8$, but there was no significant difference compared with that of $\mathrm{pH}$ $7(P>0.05)$. It was shown that the width of collagen selfassembly under neutral conditions was greater than others. 


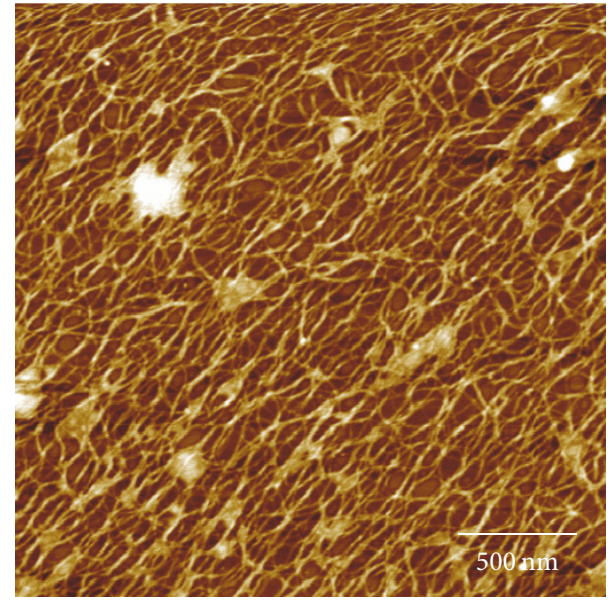

(a)

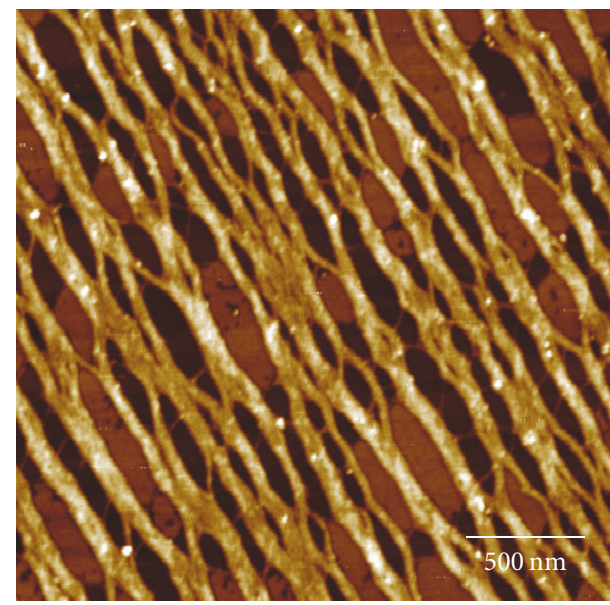

(c)

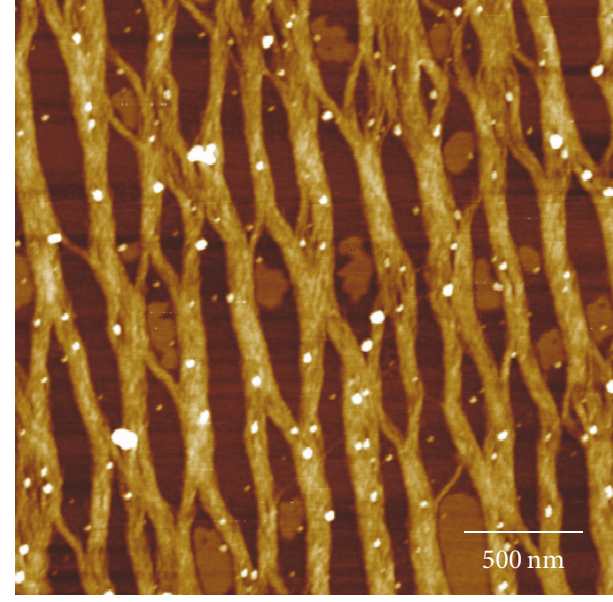

(b)

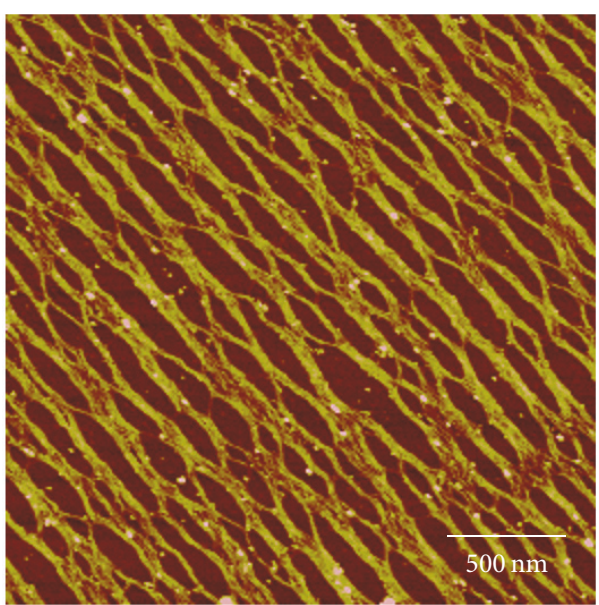

(d)

Figure 2: Typical AFM height images of collagen self-assembly at different pH values in $512 \times 512$ pixels: (a) $\mathrm{pH}$ 5.7; (b) $\mathrm{pH} 7.0$; (c) $\mathrm{pH} 8.0$; (d) $\mathrm{pH} 9.2$.

TABLE 2: Width, height, and roughness of the collagen self-assembly at different $\mathrm{pH}$ values.

\begin{tabular}{lcccc}
\hline Parameter & & \multicolumn{3}{c}{$\mathrm{pH}$ value } \\
& $\mathrm{pH}=5.7$ & $\mathrm{pH}=7.0$ & $\mathrm{pH}=8.0$ & $\mathrm{pH}=9.2$ \\
\hline Width & $53.7 \pm 7.74^{\mathrm{d}}$ & $131.35 \pm 13.93^{\mathrm{a}}$ & $112.1 \pm 10.23^{\mathrm{b}}$ & $103.5 \pm 10.09^{\mathrm{c}}$ \\
Height/nm & $2.92 \pm 0.27^{\mathrm{a}}$ & $2.45 \pm 0.08^{\mathrm{b}}$ & $2.53 \pm 0.05^{\mathrm{b}}$ & $1.73 \pm 0.13^{\mathrm{c}}$ \\
Roughness/nm & $1.01 \pm 0.19^{\mathrm{a}}$ & $0.97 \pm 0.07^{\mathrm{a}}$ & $0.98 \pm 0.11^{\mathrm{a}}$ & \\
\hline
\end{tabular}

Results $(n=20)$ are shown as mean \pm SE. Means without common superscripts $(\mathrm{a}-\mathrm{d})$ in row are different $(P<0.05)$.

The fiber width and height of the collagen self-assembly were different significantly $(P<0.05)$, which may be caused by the decrease of the height and increase of the width when the collagen solution concentration kept unchanged. The difference of Rms roughness was also significant $(P<0.05)$ at different $\mathrm{pH}$ values.

It was demonstrated that the solution of $\mathrm{pH}$ values played an important role in influencing the adsorption of anions and cations at the solid-liquid interfaces during collagen selfassembly $[21,22]$. The molecular structure of collagen is the trimer-of-phase $\left[\alpha_{1}(\mathrm{I})\right]_{2} \alpha_{2}(\mathrm{I})$, which is composed of $\alpha_{1}(\mathrm{I})$ and $\alpha_{2}$ (I) chains. Type I collagen is amphoteric electrolyte, the acidic group and alkaline group on $\alpha$ chain can combine with alkali and acid, and the acidity capacity of collagen is 2 times compared to its alkaline capacity. In acidic medium, the amide group of peptide bond in collagen molecule can function with the $\mathrm{H}^{+}$ions in the solution and form the $\mathrm{NH}^{3+}$-, and the $-\mathrm{NH}^{3+}$ - of polypeptide chain takes the most important role under this concentration of collagen solution, which led to the result that the crosslinking of collagen molecules was limited because of the repulsion between collagen molecules. The hydrophobic amino acids in the 
$0.1 \mathrm{M}$

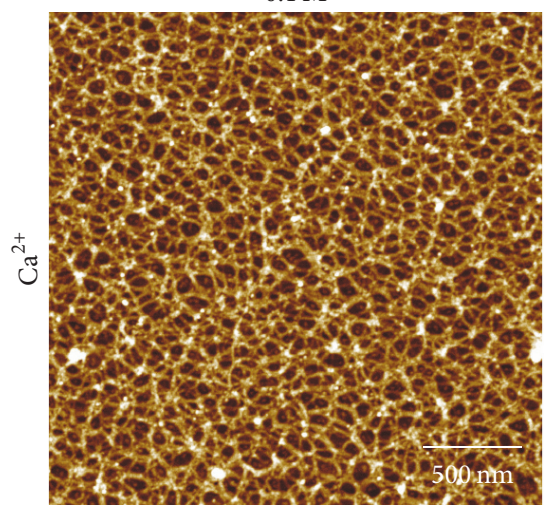

(a)

$0.1 \mathrm{M}$

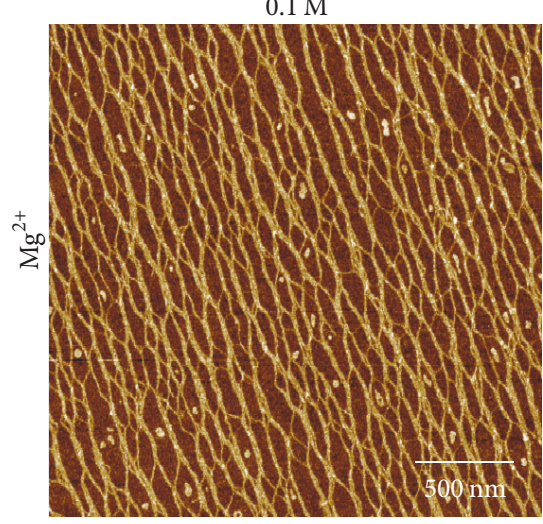

(d)

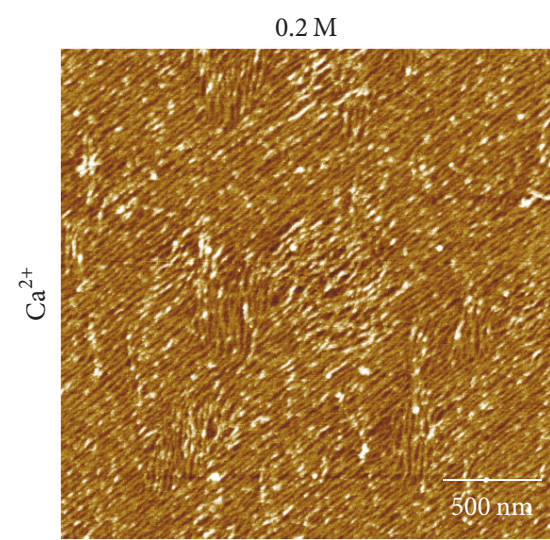

(b)

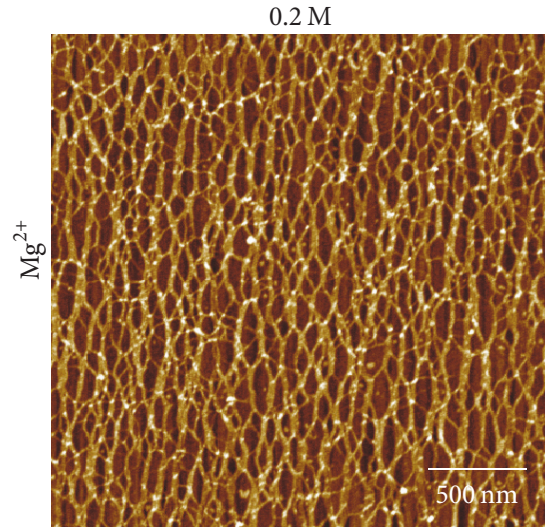

(e)

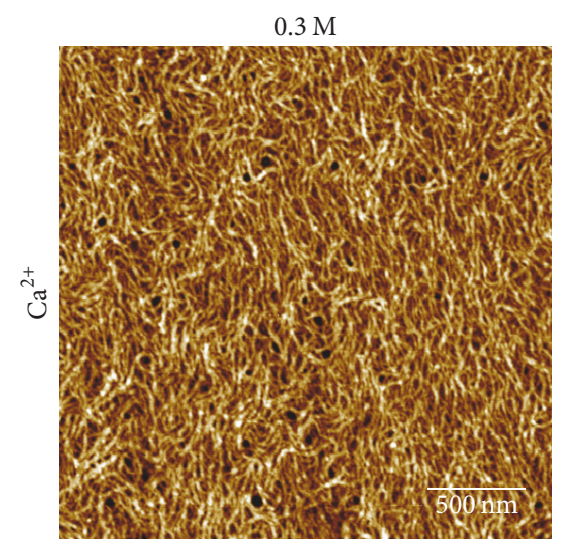

(c)

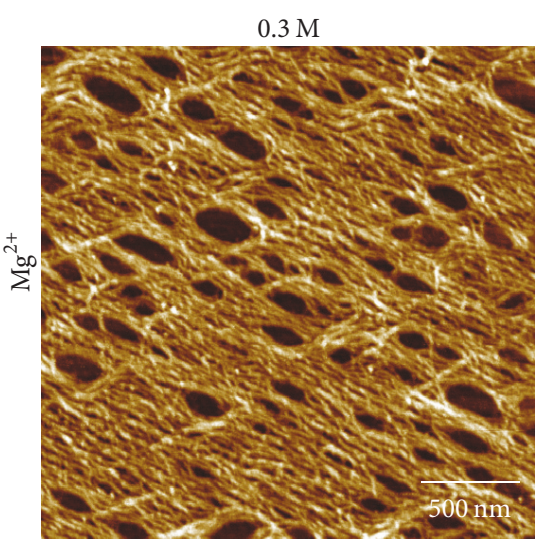

(f)

FIgURE 3: Typical AFM height images of collagen self-assembly in $\mathrm{CaCl}_{2}$ and $\mathrm{MgCl}_{2}$ solution with different ions concentration in $512 \times 512$ pixels: (a, d) $0.1 \mathrm{M}$; (b, e) $0.2 \mathrm{M}$; (c, f) $0.3 \mathrm{M}$.

polypeptide chain show its hydrophobic interaction, making the intramolecular and intermolecular force strengthen [23, 24]; then the collagen formed into irregular groups or mesh structure when collagen is saturated in the acid solution [25]. We can conclude from Table 2 that self-assembly at $\mathrm{pH} 7.0$ led to more collagen molecule being assembled and the fibrils at $\mathrm{pH} 7.0$ were thicker, and the fibrils formed at alkaline $\mathrm{pH}$ tend to be narrow in diameter, because the $\mathrm{pH}$ of collagen solution may be close the isoelectric point (pI) of collagen. At certain concentration, the collagen molecules are connected to be linear molecules for the mutual repulsion of $-\mathrm{NH}^{3+}-$, lysine, and arginine on the polypeptide chain and histidine residues $[26,27]$. But the hydrogen bonding and ionic bonding between collagen molecules were damaged by excessive acid or alkali. In the meantime, the collagen would be filled with water when $\mathrm{pH}$ value is below the isoelectric point of collagen and shows the acid expansion that is positively charged; oppositely, the collagen will be negatively charged and show alkaline expansion [27]. The moisture holding capacity of collagen varies with the $\mathrm{pH}$ values of buffer solution [26], which will help to further understand the mechanism of collagen self-assembly and provide the reference for collagen molecules assembly into fibers.
3.3. Effects of Metal Ions on Collagen Self-Assembly. To figure out the influences of metal irons on the collagen selfassembly process, the concentrations of the collagen solution were diluted at constant $0.2 \mathrm{mg} / \mathrm{ml}$. The collagen molecules assembled into fibers at different concentration of $\mathrm{CaCl}_{2}$ and $\mathrm{MgCl}_{2}$ solutions. Typical AFM height images of collagen self-assembly under different metal irons were shown in Figure 3 with apparent network topological distinction. These experiments demonstrate that the self-assembly of collagen molecules into fibrils and the formation of fibrillar networks depend in a sensitive way on the ion and its concentration. The collagen network became denser and highly crosslinked when the concentration of $\mathrm{Ca}^{2+}$ and $\mathrm{Mg}^{2+}$ irons increased gradually. Width, height, and roughness derived from the section analysis results of the AFM height images were shown in Table 3. The collagen molecules were fully crosslinked into a network structure in $\mathrm{CaCl}_{2}$ solution, as shown in Figures 3(a) and 3(b), and were crosslinked into random network structure which has smaller fiber width with high concentration of $\mathrm{Ca}^{2+}$ ions, as shown in Figure 3(c). The result indicated that difference of width of collagen fibers in different concentration of ion metal solution is significant $(P<$ $0.05)$. Specifically, the width of collagen self-assembly showed significant difference $(P<0.05)$ when the concentrations of 
TABLE 3: Width, height, and roughness of the collagen self-assembly in different metal ions concentration.

\begin{tabular}{|c|c|c|c|c|c|}
\hline \multirow{2}{*}{ Parameter } & \multicolumn{5}{|c|}{ Concentration of metal ions } \\
\hline & Category & Control (0 M) & $0.1 \mathrm{M}$ & $0.2 \mathrm{M}$ & $0.3 \mathrm{M}$ \\
\hline \multirow{2}{*}{ Width/nm } & $\mathrm{CaCl}_{2}$ & $34.50 \pm 3.14^{\mathrm{b}}$ & $33.80 \pm 2.70^{\text {by }}$ & $38.45 \pm 3.73^{\mathrm{ax}}$ & $24.05 \pm 2.96^{\mathrm{cy}}$ \\
\hline & $\mathrm{MgCl}_{2}$ & $34.50 \pm 3.14^{c}$ & $54.00 \pm 3.08^{\mathrm{ax}}$ & $49.75 \pm 3.75^{\mathrm{bx}}$ & $33.95 \pm 2.84^{\mathrm{cx}}$ \\
\hline \multirow{2}{*}{ Height/nm } & $\mathrm{CaCl}_{2}$ & $1.64 \pm 0.12^{\mathrm{b}}$ & $2.26 \pm 0.24^{\mathrm{ax}}$ & $0.93 \pm 0.09^{\mathrm{dy}}$ & $1.27 \pm 0.22^{\mathrm{cy}}$ \\
\hline & $\mathrm{MgCl}_{2}$ & $1.64 \pm 0.12^{\mathrm{a}}$ & $1.12 \pm 0.09^{\text {by }}$ & $1.33 \pm 0.17^{\mathrm{bx}}$ & $1.83 \pm 0.21^{\mathrm{ax}}$ \\
\hline \multirow{2}{*}{ Roughness/nm } & $\mathrm{CaCl}_{2}$ & $0.50 \pm 0.04^{\mathrm{b}}$ & $0.61 \pm 0.07^{\mathrm{ax}}$ & $0.22 \pm 0.02^{\mathrm{cx}}$ & $0.52 \pm 0.08^{\text {by }}$ \\
\hline & $\mathrm{MgCl}_{2}$ & $0.50 \pm 0.04^{\mathrm{b}}$ & $0.38 \pm 0.03^{\mathrm{cy}}$ & $0.39 \pm 0.03^{\mathrm{cy}}$ & $0.71 \pm 0.09^{\mathrm{ax}}$ \\
\hline
\end{tabular}

Results $(n=20)$ are shown as mean \pm SE; means without common superscripts $(\mathrm{a}-\mathrm{d})$ in row are different $(P<0.05)$. Means without common superscripts $(\mathrm{x}-$ y) in column within a parameter are different $(P<0.05)$.

$\mathrm{CaCl}_{2}$ varied from $0.1 \mathrm{M}$ to $0.3 \mathrm{M}$. Collagen molecules had begun to crosslink and aggregate in $0.1 \mathrm{M} \mathrm{CaCl}_{2}$ solution but still had little effect on the width of collagen assembly; the self-assembled fiber width increased obviously when $\mathrm{CaCl}_{2}$ solution concentration increased up to $0.2 \mathrm{M}$. At high concentration of $\mathrm{Ca}^{2+}$, the crosslink of collagen self-assembly was inhibited and shown as decreased width. The changes of metals irons resulted in the difference of structures of collagen self-assembly. Assembled fibers were parallel to each other in different concentration of $\mathrm{MgCl}_{2}$. The width of the fibers was largest at $0.1 \mathrm{M} \mathrm{MgCl}$ and decreased gradually and obviously when $\mathrm{MgCl}_{2}$ concentration increased from $0.1 \mathrm{M}$ to $0.3 \mathrm{M}$. However, the height of collagen self-assembly increased significantly $(P<0.05)$. The structure of collagen self-assembly showed obvious difference between $\mathrm{CaCl}_{2}$ and $\mathrm{MgCl}_{2}$, including roughness, height, and width values.

Collagen assembly is driven by noncovalent interaction, which is reversible upon change in solution conditions. In electrolyte solution, three polypeptide $\alpha$-chains of type I collagen were composed by abundant function groups, such as $-\mathrm{NH}_{2},-\mathrm{COOH}$, and $-\mathrm{OH}$ and other active groups can combine with metal ions and form the collagen-metal chelates [28]. Metal ions may control the structures and functions of collagen self-assembly by strengthening the folding and oligomerization of collagen molecules [29], and the interactions and the mobility of collagen molecules would be affected by the radius size of metal ions in solution [30]. The metal ions absorbed on the surfaces of collagen and mica could be gradually diffused into the water which would increase the repulsive forces among collagen molecules, collagen self-assembly, and the mica, finally quickly reducing the electrostatic attraction [27]. When the repulsive forces become the leading forces between collagen, the network collagen fiber will gradually disperse into many little fibers and finally become single collagen molecules chain. But, collagen starts to gather and crosslink at high ionic strength. On the other side, the result suggests that the crosslinking capacity of collagen in $\mathrm{MgCl}_{2}$ solution is better than that in $\mathrm{CaCl}_{2}$ solution because the radius of $\mathrm{Mg}^{2+}\left(R_{\mathrm{Mg}^{2+}}=0.66 \AA\right)$ is smaller than that of $\mathrm{Ca}^{2+}\left(R_{\mathrm{Ca}^{2+}}=0.99 \AA\right)$ [31-33], and positive charge has higher density and the steric hindrance with smaller ions radius, which can better occupy the coordination sites on collagen molecules.

\section{Conclusions}

It was shown that collagen self-assembly behavior could be regulated by the types of metal ions, ions concentration, and $\mathrm{pH}$ values of the assembly solutions. With the increase of metal ion concentrations, the width of collagen firstly increased and then decreased dramatically. When $\mathrm{Ca}^{2+}$ existed, collagen fiber crosslinked and formed into random network structure; when $\mathrm{Mg}^{2+}$ existed, the fiber structure was shown in a directional order. Different $\mathrm{pH}$ values in the buffer resulted in changes of width, height, and roughness of the collagen self-assembly at constant concentrations of collagen solutions. When the $\mathrm{pH}$ values varied from 5.7 to 7.0, the collagen fiber changes from random network structure into directional fibrous structure, and the width of the fiber increases with the increase of $\mathrm{pH}$ value; and then the width of fiber decreased with the increasing of $\mathrm{pH}$ value. Collagen has good biological characteristics and the self-assembly of collagen could be influenced by various factors. Apart from the $\mathrm{pH}$ values and metal ions in this study, there are also other factors like temperature, surfactant, sugars, and the removing of nonhelical collagen terminus. Therefore, further study is needed to study the mechanism of collagen self-assembly. In order to further and better use of collagen in related fields in medicine and food sciences, further study for improving and enhancing its strength characteristics and other properties will be done in the future.

\section{Conflicts of Interest}

The authors declare that they have no conflicts of interest.

\section{Acknowledgments}

This project was supported by National Natural Science Foundation of China (11202170, Jie Zhu), International Postdoctoral Exchange Fellowship of China Postdoctoral Council (20140059, Jie Zhu), International S\&T Cooperation Foundation of Northwest A\&F University (A213021505, Jie Zhu), Provincial Natural Science Foundation of Shaanxi (2015JQ1005, Jie Zhu), Shaanxi Postdoctoral Foundation (2015, Jie Zhu), and Sichuan Key Lab of Meat Processing, Chengdu University (17-R-05, Jie Zhu). Special thanks are due 
to Ying Wang at BioMe for her assistance with atomic force microscopy.

\section{References}

[1] J. D. Berglund, M. M. Mohseni, R. M. Nerem, and A. Sambanis, "A biological hybrid model for collagen-based tissue engineered vascular constructs," Biomaterials, vol. 24, no. 7, pp. 1241-1254, 2003.

[2] J. P. R. O. Orgel, T. C. Irving, A. Miller, and T. Wess, "Microfibrillar structure of type I collagen in situ," Proceedings of the National Academy of Sciences of the United States, vol. 103, no. 24, pp. 9001-9005, 2006.

[3] D. J. S. Hulmes, "Building collagen molecules, fibrils, and suprafibrillar structures," Journal of Structural Biology, vol. 137, no. 1, pp. 2-10, 2002.

[4] J. E. Scott, "Proteoglycan-fibrillar collagen interactions," Biochemical Journal, vol. 252, no. 2, pp. 313-323, 1988.

[5] S. Xu, A. Liu, Q. Chen, M. Lv, M. Yonese, and H. Liu, "Self-assembly nano-structure of type I collagen adsorbed on Gemini surfactant LB monolayers," Colloids and Surfaces B: Biointerfaces, vol. 70, no. 1, pp. 124-131, 2009.

[6] H. D. Jr and A. Veis, "Collagen self-assembly in vitro. Differentiating specific telopeptide-dependent interactions using selective enzyme modification and the addition of free amino telopeptide," Journal of Biological Chemistry, vol. 256, no. 14, pp. 7118-7128, 1981.

[7] J. Gross, J. H. Highberger, and F. O. Schmitt, "Collagen structures considered as states of aggregation of a kinetic unit. the tropocollagen particle," Proceedings of the National Academy of Sciences of the United States of America, vol. 40, article 679, no. 8,1954 .

[8] D. J. Hulmes, J. C. Jesior, A. Miller, C. Berthet-Colominas, and C. Wolff, "Electron microscopy shows periodic structure in collagen fibril cross sections," Biophysics, vol. 78, no. 6, pp. 3567$3571,1981$.

[9] M. J. Fullana and G. E. Wnek, "Electrospun collagen and its applications in regenerative medicine," Drug Delivery and Translational Research, vol. 2, no. 5, pp. 313-322, 2012.

[10] L. F. Wang and J. W. Rhim, "Preparation and application of agar/alginate/collagen ternary blend functional food packaging films," International Journal of Biological Macromolecules, vol. 80, pp. 460-468, 2015.

[11] J. Zhu, T. Sabharwal, L. Guo, A. Kalyanasundaram, and G. Wang, "Gloss phenomena and image analysis of atomic force microscopy in molecular and cell biology," Scanning, vol. 31, no. 2, pp. 49-58, 2009.

[12] D. C. Liu, Y. K. Lin, and M. T. Chen, "Optimum condition of extracting collagen from chicken feet and its characteristics," Asian-Australasian Journal of Animal Sciences, vol. 14, no. 11, pp. 1638-1644, 2001.

[13] D. I. Zeugolis, R. G. Paul, and G. Attenburrow, "Factors influencing the properties of reconstituted collagen fibers prior to self-assembly: Animal species and collagen extraction method," Journal of Biomedical Materials Research - Part A, vol. 86, no. 4, pp. 892-904, 2008.

[14] F. Gobeaux, G. Mosser, A. Anglo et al., "Fibrillogenesis in dense collagen solutions: a physicochemical study," Journal of Molecular Biology, vol. 376, pp. 1509-1522, 2008.

[15] T. Hayashi and Y. Nagai, "Effect of $\mathrm{pH}$ on the stability of collagen molecule in solution," The Journal of Biochemistry, vol. 73, pp. 999-1005, 1973.
[16] P. Noitup, M. T. Morrissey, and W. Garnjanagoonchorn, "In vivo self-assembly of silver-line grunt type I collagen: effects of collagen concentrations, epH and temperatures on collagen self-assembly," Journal of Food Biochemistry, vol. 30, no. 30, pp. 547-555, 2006.

[17] Y. Fan, K. Duan, and R. Wang, "A composite coating by electrolysis-induced collagen self-assembly and calcium phosphate mineralization," Biomaterials, vol. 26, no. 14, pp. 1623$1632,2005$.

[18] J. Zhu, T. Sabharwal, L. Guo, J. Lee, L. Wang, and G. Wang, "Effects of probe pollutants on morphological and mechanical measurements of muscle and collagen fibers using atomic force microscopy," Scanning, vol. 32, no. 3, pp. 113-121, 2010.

[19] M. Fang, E. L. Goldstein, E. K. Matich, B. G. Orr, and M. M. Banaszak Holl, "Type i collagen self-assembly: The roles of substrate and concentration," Langmuir, vol. 29, no. 7, pp. 23302338, 2013.

[20] F. H. Silver, J. W. Freeman, and G. P. Seehra, "Collagen selfassembly and the development of tendon mechanical properties," Journal of Biomechanics, vol. 36, no. 10, pp. 1529-1553, 2003.

[21] A. Dehsorkhi, V. Castelletto, I. W. Hamley, J. Adamcik, and R. Mezzenga, "The effect of $\mathrm{pH}$ on the self-assembly of a collagen derived peptide amphiphile," Soft Matter, vol. 9, no. 26, pp. 6033-6036, 2013.

[22] X.-P. Liao, Y. Ding, B. Wang, and B. Shi, "Adsorption behavior of phosphate on metal-ions-loaded collagen fiber," Industrial and Engineering Chemistry Research, vol. 45, no. 11, pp. 3896-3901, 2006.

[23] Y. Li, A. Asadi, M. R. Monroe, and E. P. Douglas, "pH effects on collagen fibrillogenesis in vitro: Electrostatic interactions and phosphate binding," Materials Science and Engineering C, vol. 29, no. 5, pp. 1643-1649, 2009.

[24] D. L. McBride Jr., K. E. Kadler, Y. Hojima, and D. J. Prockop, "Self-assembly into fibrils of a homotrimer of type I collogen," Matrix, vol. 12, no. 4, pp. 256-263, 1992.

[25] B. Marelli, C. E. Ghezzi, Y. L. Zhang, I. Rouiller, J. E. Barralet, and S. N. Nazhat, "Fibril formation pH controls intrafibrillar collagen biomineralization invitro and invivo," Biomaterials, vol. 37, pp. 252-259, 2015.

[26] P. J. Kaur, R. Strawn, H. Bai et al., “The self-assembly of a minifibril with axial periodicity from a designed collagen-mimetic triple helix," Journal of Biological Chemistry, vol. 290, no. 14, pp. 9251-9261, 2015.

[27] D. E. Przybyla and J. Chmielewski, "Metal-triggered radial selfassembly of collagen peptide fibers," Journal of the American Chemical Society, vol. 130, no. 38, pp. 12610-12611, 2008.

[28] F. Jiang, H. Hörber, J. Howard, and D. J. Müller, "Assembly of collagen into microribbons: effects of $\mathrm{pH}$ and electrolytes," Journal of Structural Biology, vol. 148, no. 3, pp. 268-278, 2004.

[29] C. Zhu, Y. Sun, Y. Wang, Y. Luo, and D. Fan, “The preparation and characterization of novel human-like collagen metal chelates," Materials Science and Engineering C, vol. 33, no. 5, pp. 2611-2619, 2013.

[30] A. S. Parmar, F. Xu, D. H. Pike et al., "Metal Stabilization of Collagen and de Novo Designed Mimetic Peptides," Biochemistry, vol. 54, no. 32, pp. 4987-4997, 2015.

[31] K. L. Niece, J. D. Hartgerink, J. J. J. M. Donners, and S. I. Stupp, "Self-assembly combining two bioactive peptide-amphiphile molecules into nanofibers by electrostatic attraction," Journal of the American Chemical Society, vol. 125, no. 24, pp. 7146-7147, 2003. 
[32] B. Lothenbach, D. Nied, E. L'Hôpital, G. Achiedo, and A. Dauzères, "Magnesium and calcium silicate hydrates," Cement and Concrete Research, vol. 77, pp. 60-68, 2015.

[33] G. P. Petrova, Y. M. Petrusevich, I. A. Perfil'Eva, M. S. Ivanova, and C. Syaolei, "Dynamics of collagen molecules in aqueous solutions containing metal ions with different ionic radii," Moscow University Physics Bulletin, vol. 63, no. 4, pp. 296-298, 2008. 

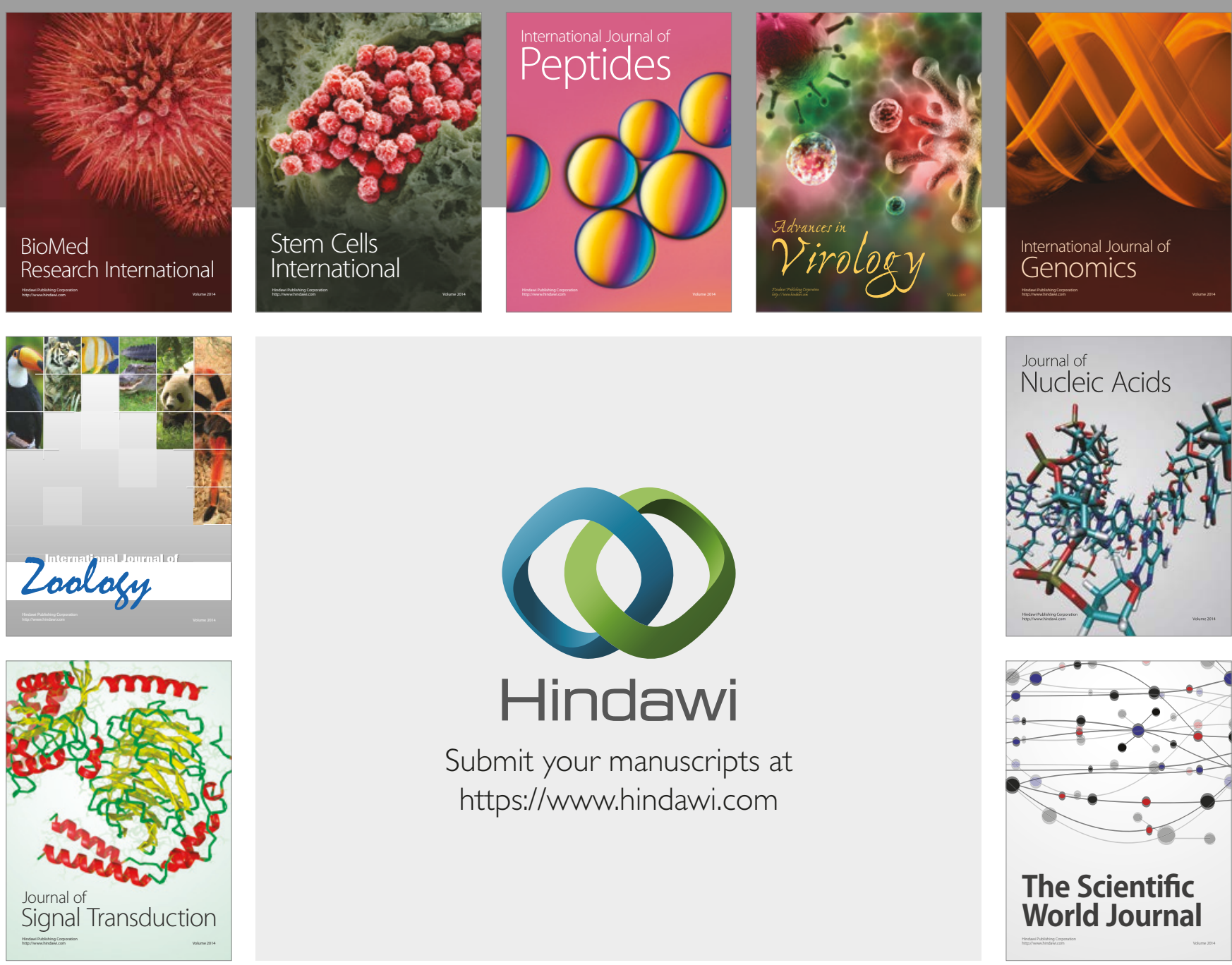

Submit your manuscripts at

https://www.hindawi.com
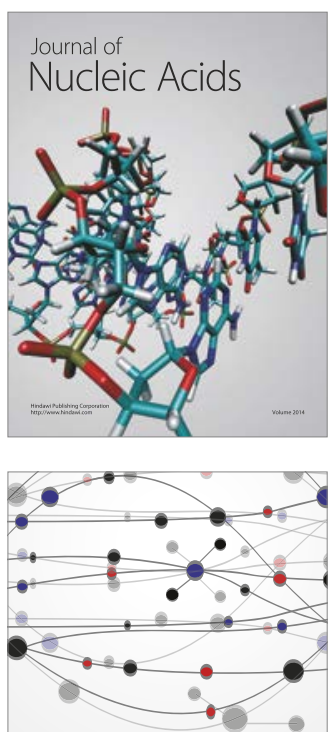

The Scientific World Journal

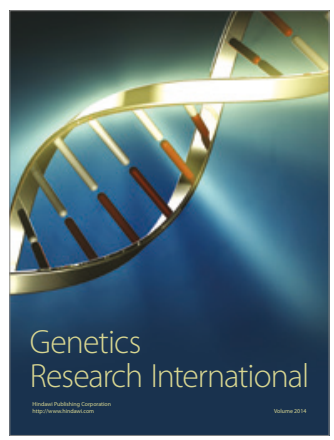

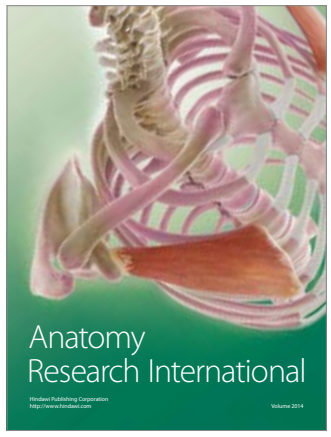

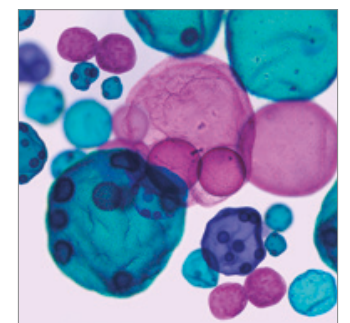

International Journal of Microbiology
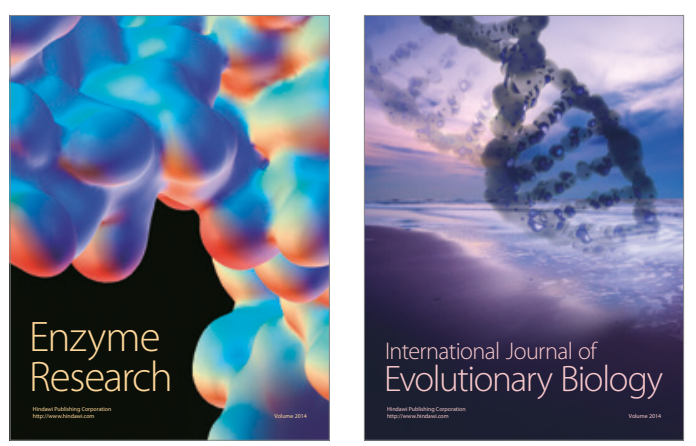
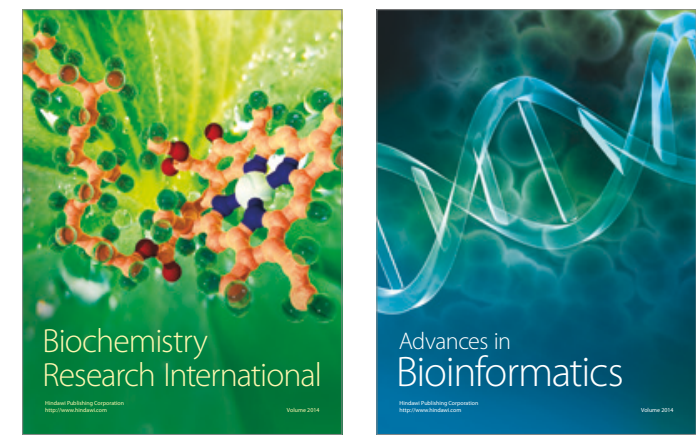

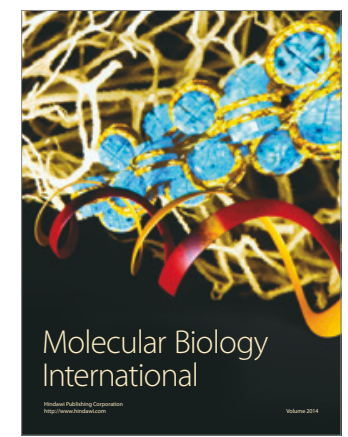

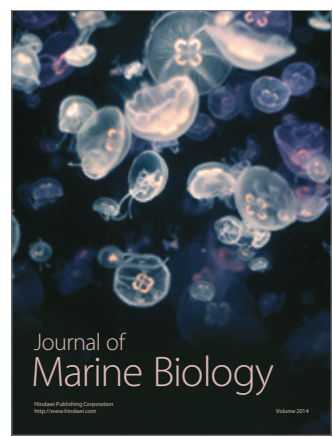

